\title{
Perancangan Urban Farming Pada Pesisir Kampung Kelembak Kepulauan Riau
}

\author{
*Stivani Ayuning Suwarlan ${ }^{1}$ \\ ${ }^{1}$ Arsitektur, Fakultas Teknik Sipil \& Perencanaan, Universitas Internasional Batam, Indonesia \\ stivani@uib.ac.id \\ *Alamat korespondensi, Masuk: 11 Feb. 2020, Direvisi: 18 Feb. 2020, Diterima: 29 Feb. 2020
}

\begin{abstract}
ABSTRAK: Ruang Terbuka Hijau (RTH) dalam perkembangannya tidak hanya berfungsi sebagai estetika dan ekologis namun juga memiliki fungsi ekonomi. Salah satu konsep RTH sehingga berfungsi ekonomi adalah dengan cara urban farming. Urban farming memiliki fokus untuk menjadikan sebuah kawasan memiliki fungsi ekonomis dan mampu menghasilkan sumber pangannya sendiri. Kampung Kelembak merupakan sebuah kawasan yang memiliki lahan pesisir pantai dengan taraf hidup masyarakat berekonomi rendah. Sehingga perlu adanya upaya perancangan bagi Kampung Kelembak agar memiliki peningkatan perekonomian melalui pemanfaatan lahan pesisir pantai dengan kondisi tanah rawa. Metodologi penelitian ini adalah deskriptif kualitatif dengan teknik pengumpulan data berupa dokumentasi, wawancara dan observasi. Solusi yang tepat bagi permasalahan Kampung Kelembak adalah melalui urban farming dengan potensinya sebagai hutan bakau yang memiliki banyak manfaat terutama manfaat bagi peningkatan ekonomi masyarakat Kampung Kelembak.
\end{abstract}

Kata kunci: Urban farming, pesisir pantai, ruang terbuka hijau

\begin{abstract}
Green Open Space in its development not only functions as aesthetic and ecological, but also has an economic function. One of the concepts of green space that functions economically is by urban farming. Urban farming has focus on making an area have economic function and able to produce its own food sources. Kampung Kelembak is a coastal area with low economic standard of living. So that there is a need for design efforts for Kelembak Village in order to have an economic increase through the use of coastal area with swampland conditions. This research using descriptive qualitative methods with collecting data technique of documentation, interviews and observations. The right solution to the problem of the Kelembak Village is through urban farming with its potential as a mangrove forest which has many benefits, especially benefits for improving the economy of the Kelembak Kampung community.
\end{abstract}

Keywords: Urban farming, coastal area, green open space

\section{PENDAHULUAN}

Ruang terbuka hijau (RTH) merupakan area baik memanjang berupa jalur ataupun area yang berkelompok yang memiliki sifat terbuka dan tempat tumbuh berbagai tanaman baik secara alamiah maupun non-alamiah [1].

Fungsi ruang terbuka hijau (RTH) pada ruang kota mulai bergeser menuju fungsi RTH produktif yang tidak lagi hanya memiliki fungsi estetika namun juga memberikan fungsi ekonomi dan mampu menopang kebutuhan masyarakat.

Salah satu konsep RTH yang dapat memberikan fungsi ekonomi adalah urban farming. Menurut Murphy [2] Sekitar 14\% dari kebutuhan pangan dunia sudah mampu dihasilkan oleh kegiatan urban farming, terbukti dari kota-kota metropolis dunia saat ini memiliki ribuan tamantaman produktif, seperti Kota New York yang memiliki lebih dari 1.000 taman kota produktif dan
Kota Berlin yang memiliki lebih dari 30.000 taman kota produktif.

Urban farming memiliki fungsi ekologis seperti penghijauan, membantu dalam menangkap $\mathrm{CO}_{2}$ dan debu, mereduksi erosi dan bencana banjir, mengurangi pemanasan kota, mengurangi kebisingan, memperlambat laju angin serta dapat memperkaya keanekaragaman ekosistem [3]. Dengan adanya RTH yang produktif, maka akan menciptakan fungsi ekonomis bagi kota tidak hanya sebatas fungsi ekologis dan estetika [4].

Di Kepulauan Riau, khususnya Batam, urban farming belum banyak dilakukan oleh masyarakat. Batam memiliki profil kawasan berupa kepulauan sehingga memiliki banyak kawasan yang berbatasan dengan laut.

Kelembak yang merupakan lokasi penelitian adalah sebuah kampung di Kelurahan Sambau, 
Kecamatan Nongsa, Kota Batam, Provinsi Kepulauan Riau dengan luas 6 hektar. Kampung Kelembak merupakan kawasan yang secara demografis memiliki wilayah rawa dan tanah datar yang berbatasan langsung dengan laut dan memiliki potensi sebagai kawasan hutan bakau.

Bakau merupakan tanaman yang dapat memecahkan ombak laut, sehingga dengan adanya penanaman bakau ini dapat mencegah terjadinya tsunami yang disebabkan oleh gempa tektonik di dasar laut. Selain itu, tanaman bakau dari akar, batang hingga buahnya memiliki banyak manfaat bagi masyarakat untuk sumber ekonomi maupun sumber pangan.

Penduduk Kampung Kelembak 90\% berprofesi sebagai nelayan dengan kondisi perekonomian yang kurang mampu. Keberadaan tanaman bakau dapat membantu dalam peningkatan ekonomi penduduk dan sesuai dengan kondisi wilayah Kampung Kelembak. Untuk itu perlu adanya perancangan kawasan terkait penanaman bakau melalui konsep urban farming.

\section{Urban Farming}

Urban farming adalah kegiatan bertanam yang meliputi tanaman pangan, peternakan, perikanan, kehutanan di dalam atau di pinggir kota. Urban farming pertama kali bermula di Amerika Serikat ketika masa perang dunia ke dua yang menyebabkan buruknya kondisi ekonomi sehingga harga sayuran sangat tinggi, sehingga dibuatlah sekitar 20 juta taman di sela-sela ruang yang tersisa. Hasil dari proyek ini adalah Amerika Serikat mampu menyediakan $40 \%$ hasil bahan pangan bagi masyarakat di masa perang dunia ke dua saat itu [5].

Urban farming di Indonesia digawangi oleh Dinas Pertanian yang melihat kondisi masyarakat miskin yang sangat berkekurangan hingga tidak terpenuhinya gizi pada sumber pangan [6].

Urban farming berfokus pada 2 (dua) hal yaitu terpenuhinya kebutuhan RTH kota dan tercukupinya pemenuhan kebutuhan pangan masyarakat kota [7]. Fungsi urban farming sebagai fungsi ekonomi dapat dilakukan dengan penjualan hasil produksi urban farming [5].

Fungsi urban farming selain sebagai produksi bahan pangan juga memiliki fungsi estetika kota yang menunjang sebagai tempat rekreasi masyarakat, dengan kata lain keberadaan urban farming dapat meningkatkan pendapatan kota [4].

Urban farming sendiri dapat dilakukan baik di lahan pribadi seperti halaman rumah penduduk maupun di lahan publik. Dengan adanya urban farming diharapkan sebuah kawasan menjadi lebih tertata dan tergunakan secara maksimal sehingga memberikan manfaat bagi masyarakat.

Kesuksesan terlaksananya urban farming harus melibatkan peran serta masyarakat agar memberikan peran secara maksimal bagi penguatan perekonomian diantaranya berupa pembukaan lapangan kerja baru, peningkatan penghasilan masyarakat serta mengurangi kemiskinan [8].

Ketersediaan pangan kawasan kota sangat bergantung pada kawasan pedesaan atau kampung pada wilayah kota tersebut [9]. Kampung merupakan kawasan permukiman yang harus dimaksimalkan pemanfaatan lahannya, seperti melalui urban farming yang dapat memanfaatkan lahan tidur melalui penanaman tanaman produktif yang mempunyai nilai ekonomi tinggi [10].

Untuk itu, kawasan kampung sangat penting diterapkan konsep urban farming agar memaksimalkan potensi kawasan sebagai penunjang pangan perkotaan dan meningkatkan perekonomian masyarakat [11].

Hutan bakau merupakan ekosistem yang berada di daerah tepi pantai yang dipengaruhi oleh pasang surut air laut sehingga memiliki permukaan selalu tergenang air laut [12].

Hutan bakau memiliki kondisi tanah yang terdiri dari lumpur dan pasir. Hutan bakau merupakan ekosistem yang sangat langka karena hanya terdapat $2 \%$ di dunia. Indonesia menjadi negara dengan ekosistem bakau terbesar, namun keberadaan hutan bakau di Indonesia saat ini berada dalam kondisi kritis dimana sekitar $68 \%$ dari total kesulurahan hutan bakau di Indonesia mengalami kerusakan [13].

Kerusakan yang dialami oleh hutan bakau sangat merugikan masyarakat di pesisir pantai karena masyarakat pesisir adalah komunitas yang langsung bersentuhan dan memahami fungsi hutan bakau sehingga wajib dilibatkan dalam keberadaan hutan bakau. Sedangkan, masyarakat umum belum begitu mengenal akan potensi hutan bakau sebagai penghasil cadangan pangan pengganti beras bagi masyarakat pesisir. Buah bakau memiliki komposisi yang menyerupai singkong dengan kandungan karbohidrat hampir 92\%. Pengolahan buah bakau yang cukup panjang dan rumit menyebabkan potensi buah bakau sebagai alternatif pangan pengganti beras kurang dikenal masyarakat luas [14]. Manfaat lain yang dimiliki oleh hutan bakau adalah menjaga stabilnya garis pantai, melindungi dari proses abrasi pantai, menahan angin kencang dari laut, filter air asin menjadi tawar dan habitat beberapa makhluk hidup. Hutan bakau juga bermanfaat sebagai paru-paru kota yang 
menghasilkan oksigen dan penyerapan $\mathrm{CO}_{2}$. Untuk manfaat ekonomi, hutan bakau menghasilkan kayu yang dapat digunakan sebagai kayu bakar, arang, bahan bangunan, bahan perabot rumah tangga, bahan baku industri pulp, kertas, tekstil, penyamak kulit, kosmetik dan zat pewarna. Manfaat lain hutan bakau adalah sebagai kawasan wisata alami pantai, tempat pendidikan, konservasi, dan penelitian [13].

Hutan bakau memiliki banyak fungsi, selain manfaat langsung sebagai sumber pangan, sumber penghidupan ekonomi bagi masyarakat seperti buah, kayu dan pohon, sumber hasil ikan dan kepiting juga manfaat tidak langsung sebagai penahan abrasi pantai dan tempat habitat beberapa makhluk hidup.

\section{LOKASI PENELITIAN}

Lokasi penelitian adalah Kampung Kelembak yang terletak di Kelurahan Sambau tepatnya Kecamatan Nongsa, Kota Batam Kepulauan Riau. Kampung Kelembak berbatasan dengan Laut Selat Malaka di bagian utara, Laut Nongsa di bagian timur, Kelurahan Batu Besar di selatan dan di barat berbatasan dengan Laut Teluk Tering. Foto dan peta lokasi Kampung Kelembak dapat dilihat pada gambar 1 dan 2 di bawah ini.

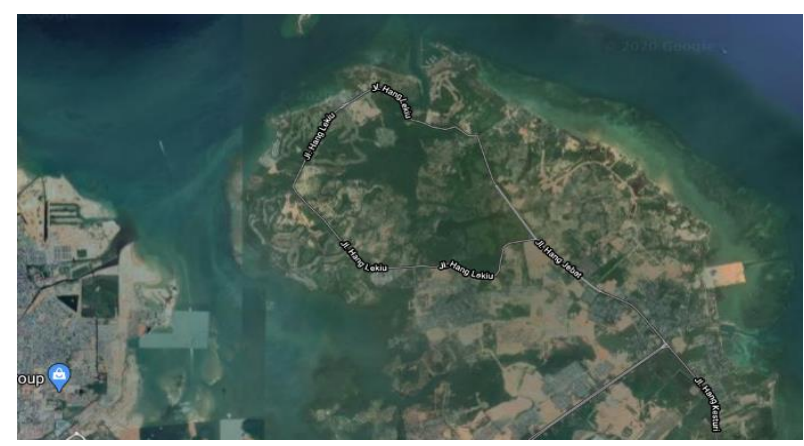

Gambar 1. Foto Udara Kampung Kelembak

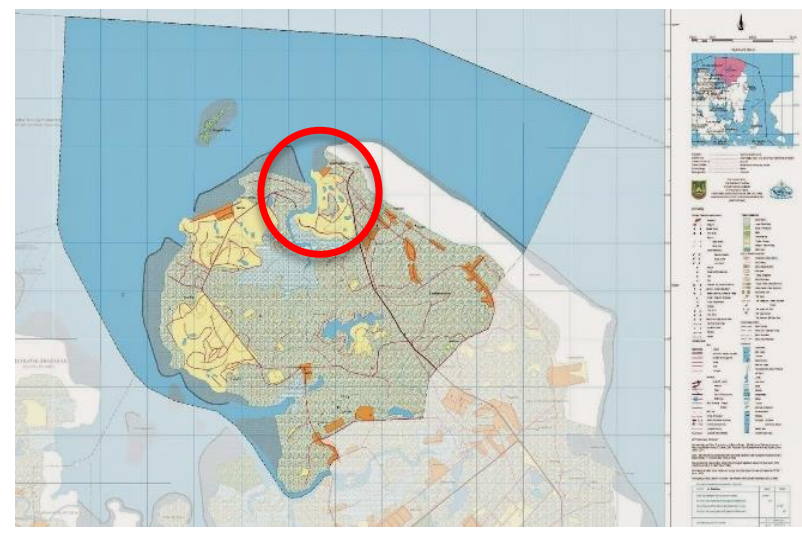

Gambar 2. Peta Administratif Kelurahan Sambau (Kampung Kelembak pada lingkaran merah)
Lokasi pada Kampung Kelembak berada tepat di pinggir pantai sehingga berbatasan langsung dengan laut seperti yang ditunjukan penulis pada gambar 3 .

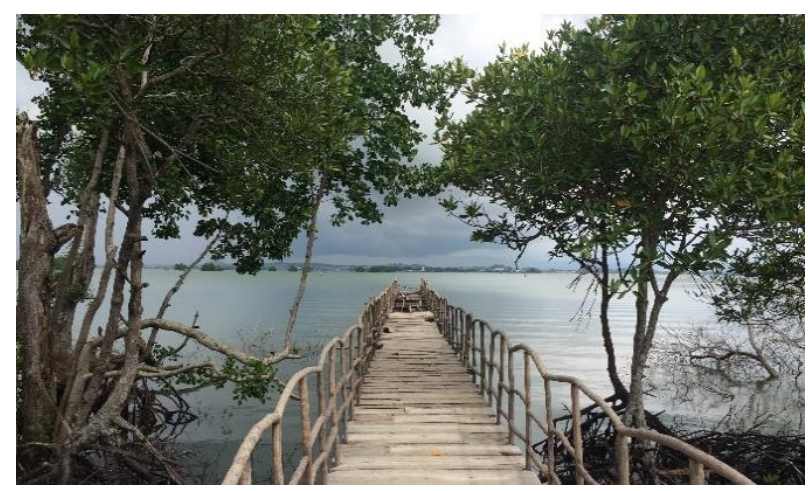

Gambar 3. Batas Laut Kampung Kelembak

Kampung Kelembak memiliki jumlah penduduk sebanyak 150 orang. Kondisi geografis Kampung Kelembak adalah lahan datar dan tanah rawa sehingga memiliki potensi bagi berkembangnya tumbuhan bakau, kondisi tanah rawa dapat dilihat pada gambar 4 di bawah ini.

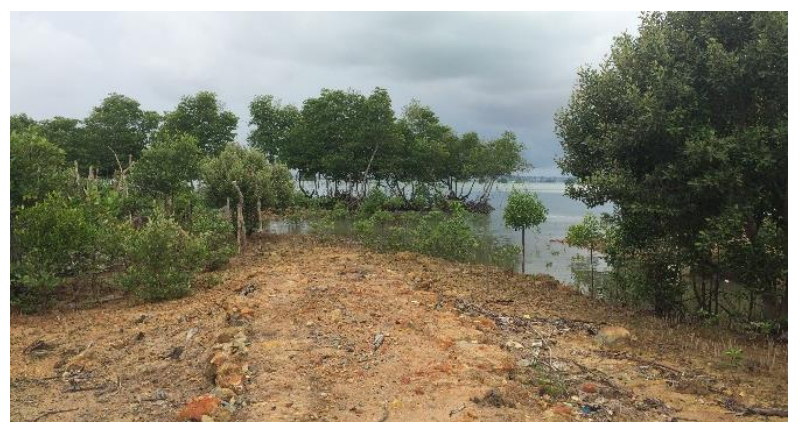

Gambar 4. Lahan Rawa Kampung Kelembak

Kampung Kelembak memiliki fungsi utama kawasan sebagai permukiman penduduk. Kondisi tanah pada kawasan permukiman adalah tanah merah yang kurang subur. Gambar 5 di bawah ini memperlihatkan kondisi eksisting Kampung Kelembak pada kawasan permukiman.

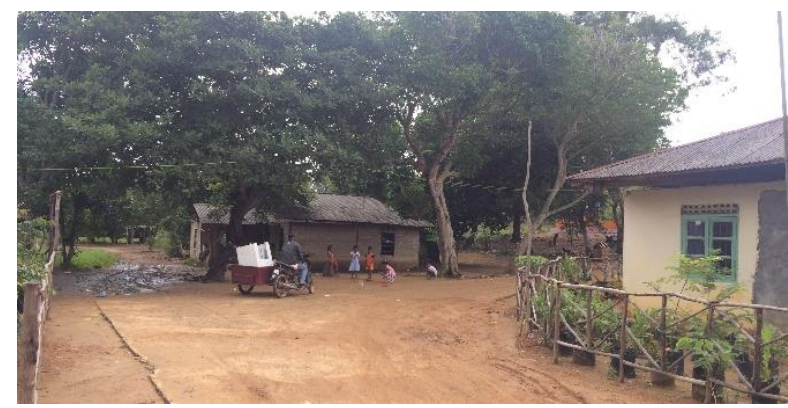

Gambar 5. Permukiman Kampung Kelembak 
Kondisi perekonomian masyarakat Kelembak masih tergolong menengah ke bawah lebih tepatnya masyarakat kurang mampu yang menggantungkan hidupnya dari sumber daya alam yaitu mencari ikan di laut sebagai nelayan. Pemerintah setempat saat ini sedang berusaha untuk meningkatkan taraf perekonomian masyarakat Kampung Kelembak dengan menghidupkan potensi Kampung Kelembak sebagai kampung wisata. Namun, menghidupkan potensi dan meningkatkan perekonomian sebuah kawasan diperlukan konsep perancangan yang matang dan tepat.

\section{METODOLOGI PENELITIAN}

Penelitian ini merupakan penelitian deskriptif kualitatif yang bertujuan untuk mendeskripsikan potensi urban farming pada kawasan pesisir Kampung Kelembak sehingga dapat dihasilkan rancangan urban farming yang tepat.

\section{Metode Pengumpulan Data}

Pengumpulan data merupakan upaya untuk mendapatkan informasi yang berhubungan dengan permasalahan pada penelitian. Secara garis besar data dapat dikelompokkan dalam dua kategori. Pertama, data primer yang didapat langsung dari objek penelitian seperti foto eksisting kawasan. Kedua, data sekunder yang didapat dari telaah kriteria perancangan pesisir pantai dengan instrumen urban farming melalui berbagai referensi. Pada rancangan ini, teknik pengumpulan data yang akan digunakan adalah dokumentasi, wawancara dan observasi.

\section{Metode Analisis dan Perancangan}

Metode analisis dan perancangan penelitian ini terdiri dari 4 (empat) tahap. Tahap pertama adalah organisasi data dengan melakukan generalisasi data-data yang telah didapatkan baik data primer maupun data sekunder. Pada tahap kedua dilakukan analisis data berdasarkan teori yang terkait tentang urban farming. Selanjutnya tahap ketiga menemukan jawaban atau solusi dari permasalahan pada kawasan penelitian. Tahap keempat adalah menemukan usulan perancangan yang akan diterapkan di kawasan penelitian.

\section{HASIL DAN PEMBAHASAN}

Hasil dari penelitian ini adalah memberikan usulan perancangan pesisir pantai Kampung Kelembak. Usulan perancangan didapatkan tidak hanya berdasarkan teori namun juga berdasarkan hasil persepsi masyarakat setempat.

\section{Persepsi dan Preferensi Masyarakat}

Peran masyarakat dalam penyediaan dan pemanfaatan RTH dimaksudkan menjamin hak masyarakat untuk mencegah terjadinya penyimpangan pemanfaatan ruang. Pengendalian pemanfaatan ruang oleh masyarakat dalam pengelolaan RTH menggunakan prinsip menempatkan masyarakat sebagai pelaku yang sangat menentukan dalam proses pemanfaatan RTH dan menghormati hak yang dimiliki masyarakat setempat serta menghargai kearifan lokal dan keberagaman sosial budayanya.

Adapun peran serta masyarakat diawali dengan eksplorasi persepsi dan preferensi masyarakat di kawasan penelitian. Persepsi dan preferensi masyarakat didapatkan dari hasil observasi lapangan dan wawancara.

Persepsi masyarakat Kampung Kelembak mengungkapkan perlu adanya tanaman produktif pada pesisir pantai yang memberikan manfaat ekonomi bagi Kampung Kelembak. Sedangkan, preferensi masyarakat Kampung Kelembak adalah penggunaan jenis tanaman produktif yang menjadi pilihan adalah tanaman bakau karena tanaman bakau sudah ada di beberapa titik pada kawasan penelitian namun belum produktif dan tersebar merata. Tanaman bakau juga sesuai dengan kondisi kawasan Kampung Kelembak dan memiliki potensi menjadi hutan bakau yang memiliki fungsi ekonomi serta wisata.

\section{Konsep Perancangan Urban Farming pada Pesisir Pantai Kampung Kelembak}

Konsep perancangan urban farming pada pesisir pantai Kampung Kelembak, merupakan hasil elaborasi dari berbagai teori yang sudah di analisis menggunakan inventarisasi data primer dan sekunder. Konsep dalam merancang kawasan penelitian yang terdiri dari 3 (tiga) aspek yaitu aspek fisik, sosial dan ekonomi.

Aspek fisik digunakan dalam pemilihan tanaman. Pada lahan rawa ditanami tanaman bakau karena letaknya di pesisir pantai. Lahan rawa dengan tanaman bakau memiliki potensi sebagai hutan bakau yang bernilai ekonomis, ekologis dan wisata hutan bakau. Sedangkan, tanaman pada lahan permukiman warga dipilih tanaman yang dapat ditanam di dalam pot karena jenis tanah di lahan permukiman adalah tanah merah dan sebagian tanah liat karena dekat dengan rawa. Jenis tanaman yang dapat ditanam di dalam pot adalah tanaman rumah tangga yang tidak terlalu besar, mudah tumbuh dan berbuah. Tanaman tersebut memiliki hasil yang dapat dikonsumsi langsung serta dapat 
dijual oleh masyarakat seperti tanaman serai, jeruk nipis, jeruk purut, cabai, tomat, lidah buaya.

Aspek sosial pada perancangan urban farming melalui penanaman hutan bakau dapat digunakan oleh masyarakat Kampung Kelembak untuk potensi wisata kampung hutan bakau. Hal ini sejalan dengan program pemerintah setempat yang ingin menjadikan Kampung Kelembak sebagai kampung wisata. Untuk aspek ekonomi, tanaman dapat dikonsumsi sendiri maupun dijual oleh masyarakat Kampung Kelembak. Buah bakau dapat diolah sebagai alternatif pengganti nasi ataupun dapat diolah menjadi industri rumah tangga makanan ringan yaitu keripik buah bakau.

\section{Usulan Perancangan}

Konsep yang sudah didapatkan yaitu meliputi aspek fisik, sosial dan ekonomi diwujudkan dalam beberapa usulan perancangan yang sesuai dengan kawasan pesisir Kampung Kelembak.

Perancangan urban farming pada lahan rawa adalah berupa hutan bakau karena kondisi tanah rawa sangat cocok dengan jenis tanaman bakau. Pada hutan bakau ini dirancang memiliki path jembatan sehingga pengunjung dapat berjalan mengitari hutan bakau. Keberadaan path jembatan juga dapat memberikan daya tarik bagi wisatawan untuk berkunjung. Berikut dapat dilihat gambar rancangan yang diusulkan untuk hutan bakau pada gambar 6 dan 7 di bawah ini.
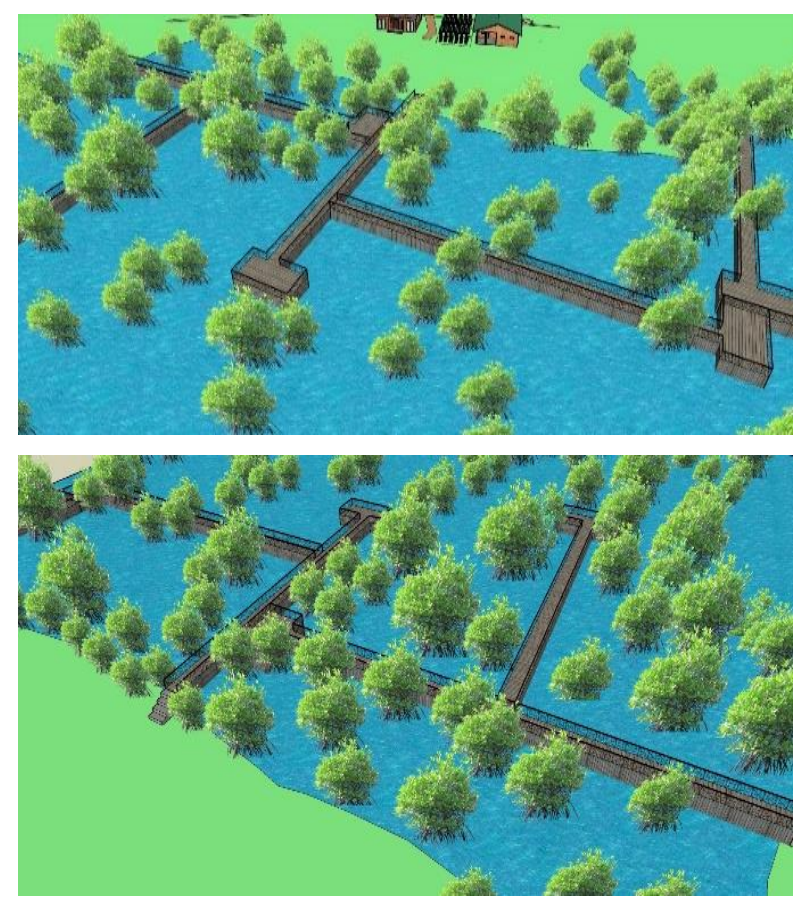

Gambar 6. Perancangan Urban Farming Hutan Bakau Pada Lahan Rawa

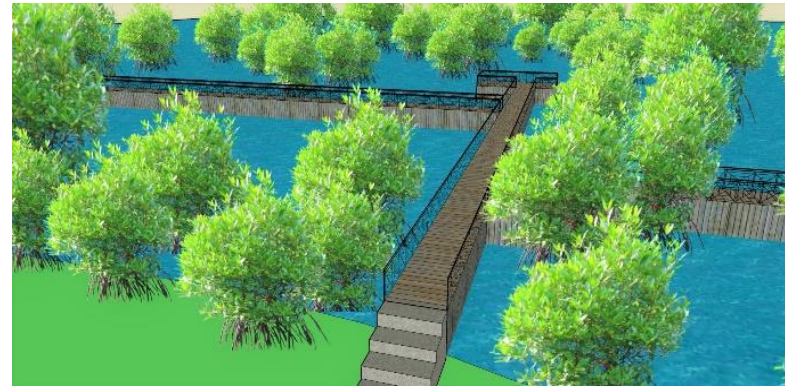

Gambar 7. Path Jembatan Kayu Mengitari Hutan Bakau Sebagai Daya Tarik Wisata

Sedangkan, perancangan urban farming pada lahan permukiman memilih jenis tanaman yang dapat dikonsumsi dan dijual oleh masyarakat. Jenis tanaman adalah tanaman rumah tangga yang dapat ditanam di dalam pot karena kondisi tanah permukiman adalah tanah merah dan liat. Urban farming pada lahan permukiman dilakukan di halaman rumah warga dengan memaksimalkan lahan kosong yang ada. Rancangan urban farming pada permukiman Kampung Kelembak dapat dilihat pada gambar 8 dan 9 di bawah ini.

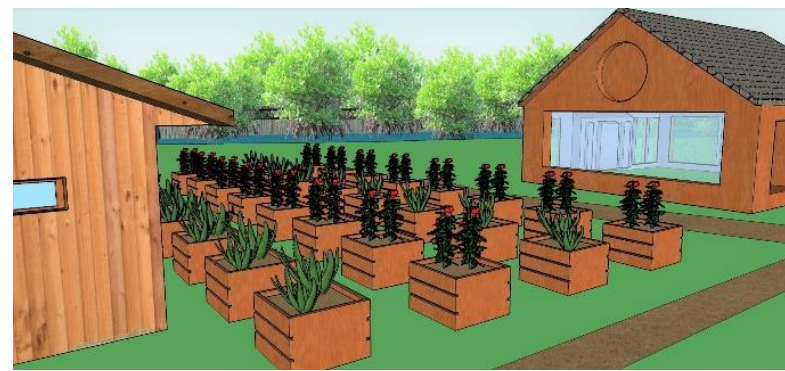

Gambar 8. Perancangan Urban Farming Tanaman Di Dalam Pot Pada Lahan Permukiman Kampung Kelembak

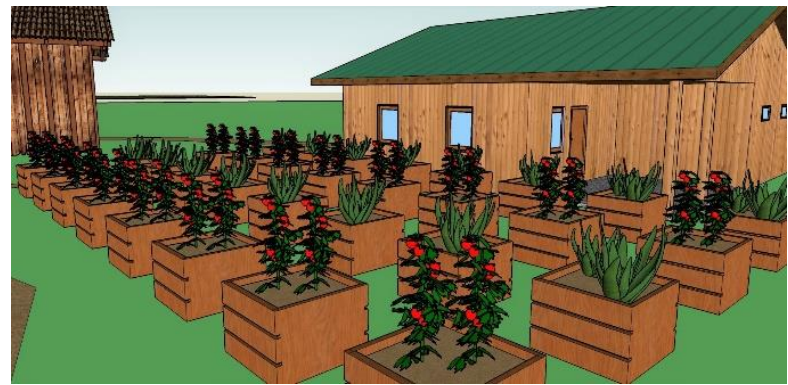

Gambar 9. Urban Farming Berada Pada Lahan Kosong Halaman Rumah Warga Kampung Kelembak

Perencanaan urban farming pada Kampung Kelembak memiliki 2 titik yaitu di titik lahan rawa dan di titik lahan permukiman. Lokasi kedua titik ini merupakan satu wilayah yang sangat berdekatan sehingga perencanaan salah satu titik harus dilaksanakan untuk keseluruhan wilayah. Kedua 
titik ini masing-masing memiliki korelasi saling terkait untuk meningkatkan perekonomian warga Kampung Kelembak melalui peningkatan sektor wisata dengan hutan bakau, penjualan hasil tanaman bakau dan pemanfaatan serta penjualan hasil tanaman dalam pot.

\section{KESIMPULAN DAN SARAN}

Pemanfaatan RTH pada sebuah kawasan pesisir pantai dapat dilakukan melalui konsep urban farming. Kampung Kelembak merupakan kawasan yang berbatasan langsung dengan laut dengan kondisi tanah rawa sehingga sangat sesuai untuk perancangan urban farming sebagai hutan bakau.

Urban farming memiliki konsep menciptakan sebuah kawasan memiliki fungsi ekonomi dan kemampuan menghasilkan sumber bahan pangan. Perancangan urban farming yang diusulkan menjadi solusi permasalahan ekonomi masyarakat Kampung Kelembak dengan menciptakan kawasan Wisata Hutan Bakau dan menciptakan sumber penghasilan tambahan dari tanaman dalam pot yang ditanaman oleh warga kampung.

Penelitian ini memiliki keterbatasan hanya sebatas usulan perancangan urban farming sehingga peneliti sangat mengharapkan adanya penelitian selanjutnya terkait implementasi urban farming pada kawasan penelitian. Harapan dari peneliti adalah urban farming dapat semakin dikenal dan meluas di Kota Batam bahkan di seluruh Provinsi Kepulauan Riau.

\section{DAFTAR PUSTAKA}

[1] Amin SFA (2019) Analisis Pemanfaatan Ruang Terbuka Hijau Pada Pemukiman Padat Di Kecamatan Rappocini Kota Makassar. LINEARS: Jurnal Teknik Arsitektur Vol. 1, No. 1: hal. 43-47.

[2] Murphy C (1999) Cultivating Havana: Urban Agriculture And Food Security In The Years Of Crisis. Development Report: Food First Institute For Food And Development Policy, No. 12.

[3] Zeeuw HD, Veenhuizen RV, Dubbeling M (2011) The Role Of Urban Agriculture In Building Resilient Cities In Developing Countries. Journal of Agricultural Science Vol. 149, No. S1: hal. 153-163.

[4] Setiawan MI, Budiyanto H, Koespiadi (2015) Pengembangan Sentra Pertanian (Urban Farming) Menggunakan Air Inflated Greenhouse. Proceeding Seminar Nasional Fakultas Teknik Sipil Universitas Narotama; 28 Februari; Surabaya; Indonesia.

[5] Belinda N, Rahmawati D (2017) Pengembangan Urban Farming Berdasarkan Preferensi Masyarakat Kecamatan Semampir Kota Surabaya. Jurnal Teknik ITS Vol. 6, No. 2: hal. 511-514.

[6] Junainah W, Kanto S, Soenyono (2016) Program Urban Farming Sebagai Model Penanggulangan Kemiskinan Masyarakat Perkotaan. Wacana Vol. 19, No. 3: hal. 148-156.

[7] Hamzens WPS, Moestopo MW (2018) Pengembangan Potensi Pertanian Perkotaan Di Kawasan Sungai Palu. Jurnal Pengembangan Kota Vol. 6, No. 1: hal. 75.

[8] Fauzi AR, Ichniarsyah AN, Agustin H (2016) Pertanian Perkotaan: Urgensi, Peranan, dan Praktik Terbaik. Jurnal Agroteknologi Vol. 10, No. 1: hal. 49-62.

[9] Puriandi F (2013) Proses Perencanaan Kegiatan Pertanian Kota yang Dilakukan oleh Komunitas Berkebun di Kota Bandung Sebagai Masukan Pengembangan Pertanian Kota di Kawasan Perkotaan. Jurnal Perencanaan Wilayah dan Kota Vol. 24, No. 3: hal. 227-240.

[10] R Mulyani HS, Suryana A, Sugiana D (2017) Communication Model In Socializing Of Urban Farming Kampung Berkebun Innovation Program in Bandung City. Edutech Vol. 15, No. 3: hal. 244.

[11] Nur'aini AD, Krisdianto J (2017) Urban Farming Dalam Kampung Vertikal Sebagai Upaya Efisiensi Keterbatasan Lahan. Jurnal Sains dan Seni Pomits Vol. 6, No. 2: hal. 95-99.

[12] Senoaji G, Hidayat MF (2017) Peran Ekosistem Mangrove Di Kota Pesisir Bengkulu Dalam Mitigasi Pemanasan Global Melalui Penyimpanan Karbon. Jurnal Manusia dan Lingkungan Vol. 23, No. 3: hal. 327-333.

[13] Majid I, Muhdar MHIA, Rohman F, et al. (2016) Konservasi Hutan Mangrove Di Pesisir Pantai Kota Ternate Terintegrasi Dengan Kurikulum Sekolah. Bioedukasi Vol. 4, No. 2: hal. 488-496.

[14] Riwayati (2014) Manfaat Dan Fungsi Hutan Mangrove Bagi Kehidupan. Jurnal Keluarga Sehat Sejahtera Vol. 12, No. 24: hal. 17-23. 